\title{
The relationship between eating behaviours, body image and BMI status among adolescence age 13 to 17 years in Meru, Klang, Malaysia

\author{
${ }^{1}$ Nur Syuhada Zofiran, M. J., ${ }^{2}$ Kartini, I., ${ }^{1}$ Siti Sabariah, B., and ${ }^{2}$ Ajau, D.
} \\ ${ }^{1}$ Department of Nutrition \& Dietetics, Faculty of Health Sciences, Universiti Teknologi MARA 42300 Puncak Alam, Selangor, Malaysia \\ ${ }^{2}$ Department of Basic Sciences, Faculty of Health Sciences, Universiti Teknologi MARA 42300 Puncak Alam, Selangor, Malaysia \\ Corresponding author: drkartiniilias@gmail.com, Telephone: +603-32584380
}

\begin{abstract}
The purpose of this study was to examine how body image, Body Mass Index (BMI), and eating attitudes were related among adolescence age 13 to 17 years old. The samples were made up of 356 adolescents, where 165 (46.3\%) were male while 191(53.7\%) were female. Body image was assessed using the Figure Rating Scale (Stunkard et al., 1983), BMI was calculated based on measures of height and weight, and eating behaviour was assessed using Eating Behaviour Patterns Questionnaire (EBPQ). This study has contributed to the knowledge on the relationship between eating behaviour, body image, and BMI among adolescence age 13 to 17 years old. This study found that, for relationship between eating behaviour and BMI status, only snacking and convenience as well as emotional eating is associated with BMI status. While for relationship between eating behaviour and body image, only body image perception was found to be associated with emotional eating. For relationship between body image and BMI status, body image perception was found to be associated with BMI status. Male adolescents were more prone to be affected by snacking and convenience as well as cultural and lifestyle. Male adolescents were prone to be affected by body image. Gender did not have an effect on BMI status. This study underlines the importance of being aware of the relationships between body image, BMI, and eating behaviour.
\end{abstract}

Key words: Eating behaviour, BMI status, body image, adolescence

\section{INTRODUCTION}

The complex relationships between body image, Body Mass Index (BMI), and eating behaviour have become an important research. Many adolescents' especially female adolescents suffer from disturbed eating behaviours such as excessive dieting and striving for thinness. The association between body image dissatisfaction may or may not be associated with elevated body mass. Each of the above variables is linked to self-satisfaction and to their effects on eating pathology, eating attitudes, body image dissatisfaction, elevated $\mathrm{BMI}$, and low selfesteem. They also affect many areas of psychological function in adolescents including depression and anxiety, leading to lack of confidence, teasing and impairment in social functioning.

According to Monir et al. (2010) eating disorder is more prevalent among overweight-obese adolescents of high social class and they conclude that social background, obesity, negative body image, depression and teasing are the main risk factors for developing eating disorder. Boyington et al., (2008) found that weight and body size preferences of African American female youths were primarily determined by the individual and her immediate social circle and were less influenced by opinions of those outside of the social circle; food choices depended on texture, taste, appearance, and context more than on nutritional value; engagement in recreational physical activity was influenced by time constraints from school and extracurricular activities and by neighbourhood safety; and celebrities were not perceived as role models for diet and physical activity habits.

Dev et al., (2009) found that overweight was more frequently found among urban female as compared to rural female adolescents because the economic status of the urban adolescents was higher than their 
rural counterparts. Furthermore, they also found that urban female adolescents have the perception of being overweight from the actual BMI value and these youths were beginning to be thin or too thin body image. Moreover, many normal healthy adolescents compared their image with thin women portrayed in the media.

Cheung et al., (2007) stated that in females, there was no evidence of a relationship between body mass index and weight control behaviours. However, there was a relationship between perceived weight and weight control behaviours where females who perceived themselves as overweight were more likely to exercise, restrict caloric intake, self medicate with diet pills, purge, or use laxatives. Meanwhile in males, there was evidence of a relationship between perceived weight, body mass index, and weight control behaviours. Males who perceived themselves as overweight or were overweight, were more likely to exercise or restrict caloric intake.

Edman and Yates (2004) concluded that having low self-satisfaction was a better indicator of disordered eating behaviour than actual physical size. The study examined a young adult samples with a mean age of 21.46 years, including two ethnic groups, Malay and Chinese. Neumark-Sztainer et al. (2010) Weightteasing was strongly associated with higher body mass index, body dissatisfaction, unhealthy and extreme weight control behaviours, and binge eating with loss of control in the girls. Parent weight-related comments particularly by mothers, was associated with many disordered eating behaviours. Mother dieting was associated with girls' unhealthy and extreme weight control behaviours. The link between body image and BMI is affected by gender. Women are frequently found to have elevated body image dissatisfaction coupled with a high BMI (Grilo \& Masheb, 2005).

Having good self-satisfaction and self esteem are important because feeling good about oneself can affect how one act. A person who has high selfsatisfaction and self esteem will make friends easily, is more in control of his or her behaviour, and will enjoy life more. Therefore, it is imperative to assess the gap of knowledge in nutrition and psychology area. Hence, this study will further scrutinize on the relationship between eating behaviour, body image and BMI status among adolescence. Along with the hypothesis for this study there was relationship between eating behaviour, body image and BMI status among adolescents age 13 years old to 17 years old.

\section{METHODS}

Participants: This study is a cross sectional study (a quantitative study) conducted from January to November 2011 to explore the relationships between eating behaviours, body image and BMI status among adolescents age 13 to 17 years in Meru, Klang, Malaysia. It was conducted in a school setting and Sekolah Agama Menengah Nurul Iman, Meru, Klang, Malaysia was selected. A total of 356 students aged of 13 to 17 years of age participated in this study. The inclusion criteria were adolescents aged 13 to 17 years old and not suffering from any chronic diseases. Meanwhile the exclusion criterion was students who suffer from chronic diseases.

Measures: Anthropometric measurements including weight, height and waist circumference were carried out on subjects. The weight and height of subjects were measured by SECA digital weight scale and poret al. stadiometer (SECA, Germany) to nearest $0.1 \mathrm{~kg}$ and $0.1 \mathrm{~cm}$, respectively. From the readings, body mass index (BMI) was calculated as weight over height square $\left(\mathrm{kg} / \mathrm{m}^{2}\right)$. An inelastic measuring tape (SECA, Germany) was used to measure waist circumferences to the nearest decimal.

To assess participants' body image, Figure Rating Scale (Stunkard et al., 1983) was used. Figure Rating Scale (Stunkard et al., 1983) consisted of two sections which were body image perception and body image desire. Each section used body shape image that corresponded to participants figure. Its scale ranges from 1 to 9 where 1 as being the thinnest body type and 9 as being the largest, most obese type. The numbers on the scale were then categorized into five groups, where images 1 and $2=$ underweight; images 3 and 4 = correct weight; image $5=$ slightly overweight; images 6 and $7=$ moderately overweight; and images 8 and $9=$ very overweight.

To assess participants eating behaviour, Eating Behaviour Patterns Questionnaire (EBPQ) adapted from Schuhundt DG, PhD. Vanderbilt University School Medicine SODA Questionnaire was used. The Eating Behaviour Patterns Questionnaire (EBPQ) consisted of a total of 50 questions that were subdivided into low fat eating (11 total questions), snacking and convenience (10 total questions), emotional eating ( 8 total questions), planning ahead ( 6 total questions), meal skipping (7 total questions), and cultural / lifestyle behaviour (9 total questions). Each question consists of 1 to 5 scale and the scale were strongly agree (5), agree (4), Neutral (3), Disagree (2), and strongly disagree (1). 
Data analysis: Statistical tests were conducted using Statistical Packages for Social Sciences (SPSS) version 18.0. Descriptive data were presented as mean or percentage. Chi square was conducted to assess the relationship between eating behaviour, body image and BMI status. Specifically an interaction was calculated between eating behaviour and BMI status as well as eating behaviour and body image along with body image and BMI status. Simple logistic regression was conducted to assess more details on the relationship between eating behaviour, body image and BMI status. In particular an interaction was calculated between eating behaviour and BMI status as well as eating behaviour and body image along with body image and BMI status. T-test was used to explore the differences between variables. In this study, the differences of eating behaviour and gender, body image and gender as well as BMI status and gender were explored. For all test, the differences were considered significant if $\mathrm{p}<0.05$.

\section{RESULT}

Table 1 shows characteristic of 356 participants who included 165 male students (46.3\%) and 191 female students (53.7\%) chosen from Sekolah Agama Menengah Nurul Iman. The mean age of the sample was 14.5 years (SD 1.348) where the age of samples ranged from 13 years to 17 years of age. Most of the samples consisted of Malay ethnicity (356 participants). Majority of participants didn't have any medical condition (91.6\%) meanwhile others $(8.4 \%)$ suffered from chronic medical condition. The mean sibling of participants was 4.72 (SD 1.83). Majority of parents' participants income was more than RM 2000 (46.9\%), followed by RM1000 to RM 1499 (23\%), RM 1500 - RM 1999 (17.4\%) and RM 500 - RM 900 $(12.6 \%)$. From the data obtained, majority of participants 68\% (242 participants) were in normal BMI status, followed by overweight $14.6 \%$ (52 participants), obese $9.6 \%$ (34 participants), thinness $7.3 \%$ (26 participants) and lastly severe thinness $0.6 \%$ (2 participants).

This study explored the relationship between eating behaviour and BMI status (Table 2). Based on the analysis that has been done, only snacking and convenience $(p=0.023,11.29)$ as well as emotional eating $(p=0.003,15.996)$ were shown to be associated with BMI status. Meanwhile low fat eating, planning ahead, meal skipping and cultural and lifestyle showed no association with BMI status. Further exploration on the relationship of eating behavior and BMI status by using simple logistic regression (Table 3) was carried out and it was found that participants that has BMI thinness tend to snacking and convenient $(p<0.05)$. As for other factor, there was no associated factor with eating behavior.

Table 1: Summary of demographic information

\begin{tabular}{ll}
\hline Demographic & Mean (SD) or \% \\
Age & $14.5(1.348)$ \\
Ethnicity & \\
Malay & $100 \%, \mathrm{n}=356$ \\
Disease & \\
No & $8.4 \%, \mathrm{n}=30$ \\
Yes & $91.6 \%, \mathrm{n}=326$ \\
Siblings & $4.72(1.83)$ \\
Parents income & \\
RM 500 - RM 900 & $12.6 \%, \mathrm{n}=45$ \\
RM 1000 - RM 1499 & $23.0 \%, \mathrm{n}=82$ \\
RM 1500 - RM 1999 & $17.4 \%, \mathrm{n}=62$ \\
> RM 2000 & $46.9 \%, \mathrm{n}=167$ \\
BMI status & \\
Severe thinness (<-3) & $0.6 \%, \mathrm{n}=2$ \\
Thinness (-3 to -2) & $7.3 \%, \mathrm{n}=26$ \\
Normal (-2 to 1) & $68 \%, \mathrm{n}=242$ \\
Overweight (1 to 2) & $14.6 \%, \mathrm{n}=52$ \\
Obese (>2) & $9.6 \%, \mathrm{n}=34$ \\
\hline
\end{tabular}

Table 2: Relationship between Eating Behaviour and BMI status

\begin{tabular}{|l|l|l|}
\hline Eating behaviour & $\mathbf{P}$ - value & $\begin{array}{l}\mathbf{X}^{2} \text { statistic } \\
\text { (df) }\end{array}$ \\
\hline Low fat eating & 0.661 & $2.412(4)$ \\
\hline $\begin{array}{l}\text { Snacking \& } \\
\text { convenience }\end{array}$ & $0.023^{*}$ & $11.29(4)$ \\
\hline Emotional eating & $0.003^{*}$ & $15.996(4)$ \\
\hline Planning ahead & 0.4 & $4.044(4)$ \\
\hline Meal skipping & 0.329 & $4.615(4)$ \\
\hline Cultural \&lifestyle & - & - \\
\hline
\end{tabular}

* Indicates significance at the .05 level

Meanwhile, study to explore the relationship between eating behaviour and body image (Table 4) showed that only body image perception was associated with emotional eating $(p=0.04,10.034)$ while low fat eating, snacking and convenience, planning ahead, meal skipping and cultural lifestyle doesn't associate with adolescent body image perception. Same goes to body image desire, it showed that low fat eating, snacking and convenience, planning ahead, meal skipping, cultural and lifestyle and even emotional eating does not associated with adolescence body image

desire. 
Table 3: Associated factors to snacking and convenient using simple logistic regression

\begin{tabular}{|l|l|l|l|l|}
\hline BMI & $\begin{array}{l}\text { Crude } \\
\text { odd } \\
\text { ratio }\end{array}$ & Wald & $\begin{array}{l}\mathbf{9 5 \%} \text { Cl } \\
\text { (df) }\end{array}$ & $\begin{array}{l}\text { p- } \\
\text { value }\end{array}$ \\
\hline Normal & & 5.070 & & 0.280 \\
\hline $\begin{array}{l}\text { Severe } \\
\text { thinness }\end{array}$ & 0.000 & 0.000 & $0.000(1)$ & 1.000 \\
\hline
\end{tabular}

\begin{tabular}{|l|l|l|l|l|}
\hline Thinness & 10.000 & 5.070 & $1.347-$ & $0.024^{\star}$ \\
& & & $74.215(1)$ & \\
\hline Overweight & 0.000 & 0.000 & $0.000(1)$ & 0.998 \\
\hline Obesity & 0.000 & 0.000 & $0.000(1)$ & 0.998 \\
\hline
\end{tabular}

${ }^{*}$ Indicates significance at the .05 level

Table 4: Relationship between Eating Behaviour and body image

\begin{tabular}{|l|l|l|l|l|}
\hline \multirow{2}{*}{ Eating behaviour } & \multicolumn{2}{|c|}{ Perception } & \multicolumn{2}{c|}{ Desire } \\
\cline { 2 - 5 } & P - value & $\mathbf{X}^{2}$ statistic (df) & P - value & $\mathbf{X}^{2}$ statistic (df) \\
\hline Low fat eating & 0.906 & $1.028(4)$ & 0.96 & $0.629(4)$ \\
\hline Snacking \& convenience & 0.435 & $3.791(4)$ & 0.904 & $1.039(4)$ \\
\hline Emotional eating & $0.04^{*}$ & $10.034(4)$ & 0.735 & $2.002(4)$ \\
\hline Planning ahead & 0.681 & $2.298(4)$ & 0.911 & $0.995(4)$ \\
\hline Meal skipping & 0.906 & $1.022(4)$ & 0.83 & $1.481(4)$ \\
\hline Cultural \&lifestyle & - & - & - & - \\
\hline
\end{tabular}

* Indicates significance at the .05 level

Table 5: Relationship between body image and BMI status

\begin{tabular}{|l|l|l|}
\hline Body image & $\mathbf{P}$ - value & $\mathbf{X}^{2}$ statistic (df) \\
\hline Perception & $0.000^{*}$ & $255.843(16)$ \\
\hline Desire & 0.091 & $23.94(16)$ \\
\hline
\end{tabular}

Table 6: Effects of eating behaviour towards gender

\begin{tabular}{|l|l|l|l|}
\hline Variables & $\begin{array}{l}\text { Male } \\
\mathbf{( n = 1 6 5 )} \\
\text { Mean (SD) }\end{array}$ & $\begin{array}{l}\text { Female } \\
(\mathbf{n = 1 9 1 )} \\
\text { Mean (SD) }\end{array}$ & P value \\
\hline Low fat eating & $3.34(0.4)$ & $3.35(0.42)$ & 0.677 \\
\hline Snacking \& convenience & $2.85(0.45)$ & $2.67(0.51)$ & $0.000^{*}$ \\
\hline Emotional eating & $3.11(0.5)$ & $3.14(0.61)$ & 0.626 \\
\hline Meal skipping & $3.02(0.51)$ & $3.15(0.53)$ & $0.017^{*}$ \\
\hline Cultural and lifestyle & $2.86(0.46)$ & $2.55(0.47)$ & $0.000^{*}$ \\
\hline
\end{tabular}

* Indicates significance at the .05 level

In this study, there are different effects between gender on snacking and convenience, meal skipping and cultural lifestyle (Table 6). It was found that in meal skipping, female adolescence was affected. Meanwhile male adolescent was affected by snacking and convenience as well as cultural and
* Indicates significance at the .05 level

The study to explore the relationship between body image and BMI status (Table 5) showed that adolescent body image perception was associated with BMI status $(p=0.000,255.843)$ whereas adolescent body image desire does not associate with BMI status $(p=0.091,23.94)$. lifestyle. In this study too, there are different effects on body image perception and body image desire between genders (Table 7 ) where male adolescents are prone to be affected by body image. Nevertheless in relationship between BMI status and gender, there was no difference between female and 
male in BMI status (Table 8). This demonstrates that Table 7: Effects of body image towards gender

\begin{tabular}{|l|l|l|l|}
\hline Variables & $\begin{array}{l}\text { Male } \\
(\mathbf{n = 1 6 5 )} \\
\text { Mean (SD) }\end{array}$ & $\begin{array}{l}\text { Female } \\
(\mathbf{n = 1 9 1 )} \\
\text { Mean (SD) }\end{array}$ & P value \\
\hline Body image perception & $2.35(0.86)$ & $1.97(0.72)$ & $0.000^{*}$ \\
\hline Body image desire & $2.38(0.54)$ & $1.74(0.52)$ & $0.000^{\star}$ \\
\hline
\end{tabular}

* Indicates significance at the .05 level

Table 8: effects of BMI status towards gender

\begin{tabular}{|l|l|l|l|}
\hline Variables & $\begin{array}{l}\text { Male } \\
(\mathbf{n = 1 6 5 )} \\
\text { Mean (SD) }\end{array}$ & $\begin{array}{l}\text { Female (n=191) } \\
\text { Mean (SD) }\end{array}$ & value \\
\hline $\mathrm{BMI}$ & $3.25(0.78)$ & $3.26(0.73)$ & 0.92 \\
\hline
\end{tabular}

\section{DISCUSSION}

Based on the data obtained from this study, it was found that only snacking and convenience $(p=0.023)$ as well as emotional eating ( $\mathrm{p}=0.003)$ were shown to be associated with BMI status. Further exploration on the relationship of eating behavior and BMI status by using simple logistic regression was carried out and it was found that participants that has BMI thinness tend to snacking and convenient $(p<0.05)$. As for other factor, there was no associated factor with eating behavior. There were a few past researches that supported the findings of the current study. On the other hand there were similar studies which did not support the findings of the current study. Forman-Hoffman (2004), found that there was a significant amount of U.S. high-school students who had abnormal eating and weight control behaviors thus increase the risk of developing eating disorder. Czyzewska, \& Graham, (2008) stated that food preferences and eating behavior did not significantly differ among participants with various BMI status. Meanwhile, Nguyen-Rodriguez et al., (2008) found that BMI was not a moderator and had no significant positive relationship towards perceived stress and emotional eating. Furthermore, there were no differences found in level of emotional eating by overweight and normal weight participants; and the proportion of emotional eaters was higher in the normal weight group rather than in the overweight group. Dialektakou and Vranas (2008) study on high school student in Greece proved that breakfast skipping was more likely to associate with overweight and obesity. gender did not have any effect on BMI status.

For eating behavior and body image, only body image perception was associated with emotional eating $(p=0.04)$. According to McNamara et al., (2007), as age increased emotional responses towards food fell and body dissatisfaction increased. Lieke et al., (2010) found that there was a significant mutual friendship group which was correlated with eating disorder risk factors, but suggested that during early-to-mid-adolescence, the levels of body image concerns and dieting within mutual friendship groups did not influence adolescents' own body image concerns and dieting. Furthermore, according to Ricciardelli et al., (2007) study, it was found that males from a range of cultural groups engaged in more extreme body change strategies and binge eating. The factors that influenced this include body build, levels of acculturation, socio-economic status, media exposure, and internalization of the muscular and lean body ideal. This finding have also been supported by Murisa et al., (2004) which stated that boys generally try to become more muscular, whereas girls attempt to lose weight. The study found that biological, psychological, and sociocultural influences made unique and significant contributions to various body image and body change/eating problems variables. Karin de Bruin et al., (2006) discovered that elite gymnasts dieted more often than controls, although they were not more negative about their body. Additionally, nonelite gymnasts also dieted as much as elite gymnast and had a more positive body image. Controls believed that 'thin is beautiful', gymnasts seemed more convinced or persuaded that 'thin is going to win'. Meanwhile Gila et al., (2004) stated that male patients with anorexia nervosa overestimated some parts of their bodies and this overestimation was related to body mass index, abnormal eating attitudes 
and drive for thinness, but not to other psychological traits.

Current study on body image and BMI status showed that adolescent body image perception do associated with BMI status $(p=0.000)$ whereas adolescent body image desire was not associated with BMI status $(p=0.091)$. Goldschmidt et al, (2011) stated that shape and weight were the two main aspects of one's scheme for self-evaluation. Lynch et al., (2007) found that regardless of ethnicity or gender, BMI was positively correlated with body concerns and weight control behaviors. Lynch et al., (2008) found that body dissatisfaction was a highly significant mediator of the relationship between body mass index (BMI) and eating disorder risk although, body dissatisfaction did not mediate the association between BMI and binge eating but it is apparently an important mediator of the association between body size and some risky weight control behaviors. Lofrano-Prado et al., (2011) revealed that BMI and fat mass increase the risk of developing eating disorder and body image dissatisfaction. Espinoza et al.,(2010) found that among Spanish adolescent girls extreme weight control behaviors were the most potent predictor of an increase in eating disturbances. With regards to body satisfaction, BMI appeared to be a potential predictor of reduced body satisfaction. Ivarsson et al., (2006) stated that girls and boys who had a lower BMI than ideal for gender and age were satisfied with their weight. Thus in all, adolescents seemed to support the current slim ideals.

In the present study, there are different effects between gender on snacking and convenience, meal skipping and cultural lifestyle. It was found that in meal skipping, female adolescence was affected. Meanwhile male adolescent was affected by snacking and convenience as well as cultural and lifestyle. McNamara et al., (2007) stated that male adolescent showed significantly higher level of 'happy' response towards food. Meanwhile, female adolescent were less 'happy' in their emotive response towards food. Meanwhile Domine' et al., (2009) stated that about half of adolescent boys may have been affected by eating concerns or involved in unhealthy eating behaviors. O'Connor et al., (2008) discovered that daily hassles were associated with an increase in unhealthy eating behavior restraint and emotional eating, among females and obese participants. This was an indication that emotional eating was the superlative moderator for hasslessnacking relationship. Zeinab et al., (2010) study found that $25.5 \%$ \& $38.6 \%$ of boys and girls reported eating disorder that was significantly correlated to body image, and bad eating habits, depression and somatic symptoms and they became more prevalent among overweight-obese adolescents. They stated that social background, obesity, negative body image, depression and teasing are the main risk factors for developing eating disorder.

This study found that there are different effects on body image perception and body image desire between genders where male adolescence are prone to be affected by body image. Berg et al., (2010) suggested that body dissatisfaction and self-esteem are strongly related in both boys and girls, across middle and late adolescence, and in nearly every weight status, racial/ethnic. Meanwhile Jaworowska, \& Bazylak (2008) found that there was a tendency to overestimate of body weight in female students, and to underestimate in male students suggest that common dissatisfaction of body weight, especially among females, who were more often engaged in dieting, regardless of not being overweight or obese according to measured actual BMI status. Consistent with the previous research by Tremblay \& Lariviere (2009) which found that 13 and 16 year-old-girls were significantly less satisfied with their body image than boys. According to Ivarsson et al., (2006) study, boys had a more positive attitude to their appearance and to their weight than girls. Downs et al. (2007) specifically found that overweight boys scored lower on body satisfaction and higher on PA compared with normal-weight boys. Yeung et al., (2010) found that female students were more weight conscious than male students. And dissatisfaction about body weight was common among normal and underweight students. Murisa et al., (2004) stated that boys generally tried to become more muscular, whereas girls attempt to lose weight.

Nevertheless in relationship between BMI status and gender, there was no difference between female and male in BMI status. It demonstrates that gender did not have any effect on BMI status. Tremblay \& Lariviere (2009) stated that there was a link between pubertal development and obesity in girls but not in boys. Lemon et al., (2008) found that female adolescents were more likely than male to consider themselves to be overweight across each BMI category, and were more likely to report attempting to lose weight. However, perceiving oneself to be overweight was a strong correlation for weight loss attempts for both genders. 
Am. J. Food. Nutr, 2011, 1(4): 185-192

CONCLUSION: There are several limitations to the present study that should be addressed in future research. First, the small sample size of the study limits the statistical power. Thus, in future study larger sample is needed in order to generalize the results to general populations. Secondly, the short duration of time, in which the data collection was conducted for one day might have hindered the application of the results to the general population. Thirdly, the questionnaires were self-reporting and there were possibilities that the participants completed the questionnaire together with peer group while comparing and sharing the responses. Fourthly, the conclusions that were based on correlation analyses needed to be viewed with some caution. A relationship between these variables can be determined but this did not provide information on the causal mechanisms. The fifth limitation was the lack of a quality of life measure. It had been seen in past research that dissatisfaction with body image, elevated BMI, and disturbed eating behaviour could have an effect on an adolescent's quality of life. A measure of quality of life would have added to the results as a direct relationship between what the adolescence in the present sample experience in body image, BMI and eating behaviour could be related to their quality of life. With these limitations in mind, all the results obtained should be made with caution. Future research should be tested with larger sample, more socio-demographically population and longer duration of time.

This study found that, in the relationship between eating behaviour and BMI status, only snacking, convenience and emotional eating were associated with BMI status. As far as relationship between eating behaviour and body image was concerned, it was found that only body image perception was associated with emotional eating. For relationship between body image and BMI status, body image perception was associated with BMI status. Male adolescents were more prone to be affected by snacking and convenience as well as cultural and lifestyle. Male adolescents were also prone to be affected by body image. Gender did not have an effect on BMI status. This study underlines the importance of being aware of the relations between body image, BMI, and eating behaviour.

ACKNOWLEDGEMENT: The authors' appreciate and acknowledge the support and help of Noor Hasyimah, Munirah, Nazirah Zuman, Nuri Naqieyah, Nur Hidayah, Roszanadia, Siti Nurul Emah, Mohd
Khir, Muhammad Basir, Mohd Bukhari and Mohamad Tarmizi prior to data collection assistance.

\section{REFERENCES}

Berg, P. A., Mond, J., Eisenberg, M., Ackard, D., \& Neumark-Sztainer, D. (2010). The link between body dissatisfaction and self-esteem in adolescents: Similarities across gender, age, weight status, race/ethnicity, and socioeconomic status. Journal of Adolescent Health 47: 290-296.

Boyington, J. E. A., Carter-Edwards, L., Piehl, M., Hutson, J., Langdon, D., \& McManus, S. (2008). Cultural attitudes toward weight, diet, and physical activity among overweight African American girls. Prev Chronic Dis ,5(2).

Cheung, K. P. C. H., Ip, P. L.S., Lam, S. T., \& Bibby, H. (2007). A study on body weight perception and weight control behaviours among adolescents in Hong Kong. Hong Kong Med Journal 13: 16-21.

Czyzewska, M., \& Graham, R. (2008). Implicit and explicit attitudes to high- and low-calorie food in females with different BMI status. Eating Behaviors 9: 303-312.

Dev, R. D. V., Permai, V., \& Omar Fauzee, M. S. (2009). Rural urban dieferences in body image perception, Body Mass Index and dieting behavior among Malay adolescence Malaysian schoolgirl. European Journal of Scientific Research 34: 69-82.

Dialektakou, K. D., \& Vranas, P. B. M. (2008). Breakfast skipping and body mass index among adolescents in Greece: whether an association exists depends on how breakfast skipping is defined. $J A m$ Diet Association 108: 1517-1525.

Domine', F., Berchtold, A., Akre', C., Michaud, P., \& Suris, J. (2009). Disordered eating behaviors: what about boys? Journal of Adolescent Health 44: 111-117.

Downs, D. S., DiNallo, J. M., Savage, J. S., \& Davison, K. K. (2007). Determinants of eating attitudes among overweight and nonoverweight adolescents. Journal of Adolescent Health 41: 138-145.

Edman, J. L., \& Yates, A. (2004). Eating attitudes among college students in Malaysia: An ethnic and gender comparison. European Eating Disorders Review 12: 190-196.

Espinoza, P., Penelo, E., \& Raich, R. M. (2010). Disordered eating behaviors and body image in a longitudinal pilot study of adolescent girls: What happens 2 years later?. Body Image 7: 70-73.

Forman-Hoffman, V. (2004). High prevalence of abnormal eating and weight control practices among U.S. highschool students. Eating Behaviors 5: 325-336.

Gila, A., Castro, J., Cesena, J., \& Toro, J. (2005). Anorexia nervosa in male adolescents: body image, eating 
attitudes and psychological traits. Journal of Adolescent Health 36: 221-226.

Goldschmidt, A., Wilfley, D. E., Eddy, K. T., Boutelle, Zucker, K. N., Peterson, C. B., Celio-Doyle, A., \& Grange, D. L. (2011). Overvaluation of shape and weight among overweight children and adolescents with loss of control eating. Behaviour Research and Therapy 49: 682-688.

Grilo, C. M., \& Masheb, R. M. (2005). Correlates of body image dissatisfaction in treatment-seeking men and women with binge eating disorder. International Journal of Eating Disorders 38: 162-166.

Ivarsson, T., Svalander, P., Litlere, O., \& Nevonen, L. (2006). Weight concerns, body image, depression and anxiety in Swedish adolescents. Eating Behaviors 7: $161-175$.

Jaworowska, A., \& Bazylak, G. 2009. An outbreak of body weight dissatisfaction associated with self-perceived BMI and dieting among female pharmacy students. Biomedicine \& Pharmacotherapy 63: 679-692.

Karin de Bruin, A. P., Rao^ul Oudejans, R. D., \& Bakker, F. C. (2007). Dieting and body image in aesthetic sports: A comparison of Dutch female gymnasts and nonaesthetic sport participants. Psychology of Sport and Exercise 8: 507-520.

Lemon, S. C., Rosal, M. C., Zapka, J., Borg, A., \& Andersen, V. (2009). Contributions of weight perceptions to weight loss attempts: Differences by body mass index and gender. Body Image 6: 90-96.

Lieke, C. S., Woelders, M. A., Larsen, J. K., Scholte, R. H. J., Cillessen, A. H. N., \& Engels, R. C. M. E. (2010). Friendship group influences on body dissatisfaction and dieting among adolescent girls: a prospective study. Journal of Adolescent Health 47: 456-462.

Lofrano-Prado, M. C., Prado, W. L., Piano, A., Tock, L., Caranti, D. A., Oller do Nascimento, C. M., Oyama, L. M., Tufik, S., Túlio de Mello, M., \& Dâmaso, A. R. (2011). Eating disorders in adolescents: Correlations between symptoms and central control of eating behavior. Eating Behaviors 12: 78-82.

Lynch, W. C., Heil, D. P., Wagner, E., \& Havens, M. D. (2008). Body dissatisfaction mediates the association between body mass index and risky weight control behaviors among White and Native American adolescent girls. Appetite 51: 210-213.

Lynch, W. C., Heil, D. P., Wagner, E., \& Havens, M. D., (2007). Ethnic differences in BMl, weight concerns, and eating behaviors: Comparison of Native American,
White, and Hispanic adolescents. Body Image 4: 179190.

McNamaraa, C., Haya, P., Katsikitisb, M., \& Chur-Hansenc A. (2008). Emotional responses to food, body dissatisfaction and other eating disorder features in children, adolescents and young adults. Appetite 50: 102-109.

Monir, Z. M., Khalifa, A. G., Hassaballa, F., Tawfeek, S., Abdelmonem, M., Shady, M. A., \& Mansour, M. (2010). Eating Behavior and Problems in Egyptian Adolescents; Relation to Dietary Intake. Journal of American Science 6(12): 1145-1159.

Murisa, P., Meestersb, C., Willemien van de Blomb, \& Mayera, B. (2005). Biological, psychological, and sociocultural correlates of body change strategies and eating problems in adolescent boys and girls. Eating Behaviors 6: 11-22.

Neumark-Sztainer, D., Bauer, K. W., Friend, S., Hannan, P. J., Story, M., \& Berge, J. M. (2010). Family weight talk and dieting: How much do they matter for body dissatisfaction and disordered eating behaviors in adolescent girls?. Journal of Adolescent Health 47: 270-276.

Nguyen-Rodriguez, S. T., Chou, C. P., Unger, J. B., \& Spruijt-Metz, D. (2008). BMI as a moderator of perceived stress and emotional eating in adolescents. Eating Behaviors 9 238-246.

O'Connor, D. B., Jones, F., Conner, M., McMillan, B., \& Ferguson, E. (2008). Effects of daily hassles and eating style on eating behavior. Health Psychology 27(1): 20-31.

Ricciardelli, L. A., McCabe, M. P., Williams, R. J., \& Thompson, J. K. (2007). The role of ethnicity and culture in body image and disordered eating among males. Clinical Psychology Review 27: 582-606.

Tremblay, L., \& Lariviere, M. (2009). The influence of puberty onset, Body Mass Index, and pressure to be thin on disordered eating behaviors in children and adolescents. Eating Behaviors 10: 75-83.

Yeung, W. T. L. (2010). Gender perspectives on adolescent eating behaviors: A study on the eating attitudes and behaviors of junior secondary students in Hong Kong. Journal of Nutrition Education and Behavior 42 (4).

Zeinab, M. M., Abla, G. K., Fawzya, H., Sawsan, T., Mohamed, A., Moones, A. S., \& Manal, M. (2010). Eating behavior and problems in Egyptian adolescents; relation to dietary intake. Journal of American Science 6(12). 